\title{
FRANTZ FANON NO BRASIL: UMA RELEITURA DA SUA RECEPÇÃO PELO PENSAMENTO NEGRO FEMINISTA
}

\author{
FRANTZ FANON IN BRAZLL: A RE-READING OF HIS RECEPTION BY FEMINIST BLACK THOUGHT
}

\section{RESUMO}

Este artigo propõe uma releitura da recepção de Franz Fanon no Brasil em dois períodos específicos entre 1960-1970 e 1980-1990. Em suma, os aportes metodológicos deste escrito se baseiam em buscas no Google Scholar, os resultados obtidos foram organizados em dois quadros, por um lado, novas abordagens foram introduzidas ao longo das últimas cinco décadas desde a recepção de Frantz Fanon no cenário brasileiro, por outro lado, Lélia González e Neusa Santos Souza, por exemplo, não foram identificadas como autoras citadas pelos principais comentadores de Fanon. A ideia de tradução aqui é utilizada em chave ampliada, no entanto, não limita a nossa compreensão de que trata-se de um campo hegemonicamente masculino e sexista, e ao assumi-la como uma prática política buscamos refletir sobre os dividendos patriarcais e racistas do campo editorial e acadêmico. Na análise deste artigo, fundamentada no pensamento negro feminista e/ou das intelectuais negras, confirmamos que há uma genealogia masculinista em disputa pelos fanonismos que invisibiliza as intelectuais negras. Afinal, se Lélia González e Neusa Santos Souza dialogam com o pensamento fanoniano desde a tradução dos livros Peau Noire, Masques Blancs (Pele Negra, Máscaras Brancas) e Les Damnés de la Terre (Os Condenados da Terra), quais são as razões para não associá-las às teorias políticas em voga nos movimentos sociais negros e/ou nos discursos acadêmicos?

Palavra-chaves: Frantz Fanon. Tradução. Pensamento Negro Feminista. Mulheres Negras.

\begin{abstract}
This article proposes a re-reading of the reception of Franz Fanon in Brazil in two specific periods between 1960-1970 and 1980-1990. In short, the methodological contributions of this paper are based on searches in Google Scholar, the results obtained were organized in two frames, on the one hand, new approaches were introduced over the last five decades since the reception of Frantz Fanon in the Brazilian scenario, for On the other hand, Lélia González and Neusa Santos Souza, for example, were not identified as authors cited by Fanon's main commentators. The idea of translation here is used in an enlarged key, however, it does not limit our understanding that it is a hegemonically male and sexist field, and in assuming it as a political practice, we seek to reflect on the patriarchal and racist dividends of the editorial and academic field. In the analysis of this article, based on Black

\section{Rosânia do Nascimento}

Bacharela em Antropologia pelo Departamento de Antropologia da Universidade de Brasília (DAN/ ICS/UnB) e Mestranda pelo Programa de Pós-Graduação em Antropologia Social (PPGAS/DAN/UnB). E-mail: rosaniaoliveirao1@gmail.com
\end{abstract}


Feminist Thought and/or Black intellectuals, we confirm that there is a masculinist genealogy in dispute for the fanonisms that invisible Black intellectuals. After all, if Lélia González and Neusa Santos Souza talk with Fanonian thinking since the translation of the books Peau Noire, Masques Blancs (Black Skin, White Masks) and Les Damnés de la Terre (The Damned of the Earth), what are the reasons for not associate them with the political theories in vogue in Black Social Movements and/ or academic discourses?

Keywords: Frantz Fanon. Translation. Female Black Thought. Black Women.

Neste artigo propomos uma releitura da recepção da tradução do martinicano Frantz Fanon no Brasil em dois momentos específicos entre 1960 a 1970 e 1980 a 1990 a fim de afirmar a sua influência no pensamento crítico da filósofa Lélia González e da psicanalista Neusa Santos Souza. Ao perceber que há uma genealogia masculinista em disputa pelos fanonismos no Brasil, demonstramos que essas duas intelectuais negras estiveram em diálogo com Fanon, pois havia versões para o português brasileiro e espanhol dos livros de Frantz Fanon em circulação entre os movimentos sociais negros e o movimento de mulheres negras. Assim, a ausência destas intelectuais brasileiras nesses debates entre as décadas de 1980 a 1990 confirmam o racismo e o sexismo operante nas disputas pelos Estudos Pós-coloniais e Decoloniais.

Desde a década de 1990, diversas autoras têm desvelado o processo do silenciamento das vozes femininas negras no Movimento Négritude, em especial, Tanella Boni (2014) em Femmes en Négritude: Paulette Nardal et Suzanne Césaire, afirma que erroneamente tal movimento é associado a ideia dos "pais" como se fosse um acaso o encontro, em Paris, do martinicano Aimé Césaire, do senegalês Léopold Sédar Senghor e do guianense Léon-Gontran Damas. Assim, ao alinhar também nossas análises com a estadunidense Tracy Denean Sharpley-Whiting autora de Femme Négritude: Jane Nardal, La Dépêche Africaine, and the francophone New Negro, buscamos evidenciar o sexismo dos comentadores e interlocutores fanonianos no Brasil. Esta análise pauta-se pelo diálogo com o pensamento negro feminista e/ou das intelectuais negras, pois "só reivindica comida quem tem fome, e, dificilmente essa problematização seria levada a cabo por um homem, o qual muitas vezes não percebe a ausência de mulheres por estar ocupando a posição de privilégio" (ROCHA, 2018: 33).

Esta releitura da recepção de Frantz Fanon no Brasil propõe desvelar as lacunas em relação a associação masculinista dos comentadores e acadêmicos brasileiros na recepção do pensamento africano ou diaspórico. Dito desta forma, nosso estudo não está alinhado aos Estudos da Tradução e Estudos de Gênero, campo interdisciplinar construído por tradutoras feministas e demais estudiosas. Como advertido por Monique Pfau (2012), a tradução feminista tem sido uma estratégia profícua para dialogar de imediato com intelectuais brasileiras e estrangeiras, afinal, a internacionalização da tradução feminista deve ser "representada através da 'língua franca'; ou seja, o discurso deve conseguir ser publicado em uma língua de amplo 
acesso, conseguindo assim conquistar seu 'visto' para ser universalmente lido por diversas culturas diferentes além do lugar onde nasceu” (PFAU, 2012: 56). Neste artigo o sentido de tradução segue em chave ampliada, no entanto, não limita a nossa compreensão de que trata-se de um campo hegemonicamente masculino e sexista, e ao assumi-la como uma prática política buscamos refletir sobre os dividendos sexistas do campo editorial e acadêmico.

Em contrapartida, quando se refere ao pensamento de mulheres africanas ou diaspóricas observa-se um silenciamento agudo, muitas vezes, o movimento destas mulheres ou a participação de algumas delas em círculos e movimentos artísticosculturais e filosóficos não é mencionada ou lembrada. Em diálogo com Tanella Boni (2014: 63) algumas indagações ressoam, afinal, "o que aconteceu? Elas escrevem, elas pensam, mas elas não são ouvidas?". Já faz algum tempo que intelectuais negras têm refletido sobre o enigma sexista nos movimentos sociais negros e acadêmico em âmbito internacional e nacional. Algumas reflexões são emergentes nesse campo, afinal, quais são os sentidos ou lógicas nas falhas na comunicação e transmissão da tradução de autoria feminina negra no Brasil? É curioso que o leitor fanoniano tome o sociólogo Antonio Sérgio Alfredo Guimarães (2008) como a principal referência e não perceba a reprodução de uma genealogia masculina. Aliás, o próprio Guimarães (2008) cita uma coletânea organizada por Tracy Denean Sharpley-Whiting em coautoria com Lewis Gordon e Renée White, mas ao que nos parece até o momento é que as intelectuais têm sido negligenciadas no "mapa panorâmico dos fanonismos", expressão usada pelo sociólogo Deivison Faustino (2015: 22).

Ao mesmo tempo, se o leitor se atentar às notas de rodapé de Guimarães (2008) notar-se-á que tal produção se insere nas reflexões do Colloque Penser aujourd'hui à partir de Frantz Fanon, acontecido em 2007, na França. O evento reuniu entre outras convidadas, por exemplo, a antropóloga argelina Tassadit Yacine-Titouh e Mireille Fanon-Mendès-France, jurista e filha de Frantz Fanon, o não conhecimento dessas intelectuais confirma, mais uma vez, a reprodução da transmissão do pensamento fanoniano e da tradução dos seus clássicos pelo crivo sexista. Por outro lado identificar em que contexto político os autores considerados "especialistas" em Frantz Fanon se inserem nos possibilita melhores compreensões investigativas e analíticas para afirmar os seus dividendos patriarcais.

Ao sistematizar nossas reflexões, observamos que realizar uma revisão teórica não seria o suficiente para atingir nosso objetivo principal, pois não faltam textos produzidos em português sobre a intersecção do pensamento e práxis revolucionária de Frantz Fanon com os demais pensadores, políticos, intelectuais, como, por exemplo, Jean-Paul Sartre, Paulo Freire, Clóvis Moura, Amílcar Cabral, e agora mais recentemente, aos nomes masculinos dos Estudos Decoloniais e ao filósofo camaronês Achille Mbembe (Cf. BERNARDINO-COSTA et. al., 2018). Os aportes metodológicos adotados compreendem dois momentos a fim de subsidiar a revisão teórica proposta; o primeiro, foram feitas pesquisas avançadas no sistema eletrônico Google Acadêmico

1 No original, “Que s'est-il donc passé? Elles écrivent, elles pensent, mais sont-elles entendues?” (BONI, 2014: 63). 
classificadas pelo idioma (português brasileiro), relevância (número de vezes em que os resultados aparecem citados em artigos relacionados) e períodos específicos (entre 1960-1970 e 1980-1990). O critério destes dois períodos específicos, em especial, converge com a data da primeira tradução do livro de Frantz Fanon, em 1968, e com o desenvolvimento dos movimentos sociais negros e movimentos de mulheres negras no decorrer dos anos 1970 e 1980, ou seja, mesmo lapso temporal da atividade intelectual de Lélia González e Neusa Santos Souza.

No segundo momento, a organização dos dados obtidos ilustra o corpo deste artigo estão agrupados em dois quadros segmentados em três colunas, respectivamente, referentes às abordagens conceituais, aos dados das publicações, e a última coluna demarca as áreas de interesses a fim de entender como Frantz Fanon foi apropriado ao longo dos últimos cinco decênios por estudos interdisciplinares. Assim como a revisão teórica, o sistema de pesquisas Google Acadêmico não foi pensado como um filtro imparcial ou com total acuidade, estamos cientes das limitações dessa metodologia como a restrição ao lastro acadêmico que exclui, na maioria das vezes, a produção militante ou ativista de Lélia González e a produção técnica (clínica) de Neusa Santos Souza, a segunda limitação é que muitas obras publicadas no decorrer dos períodos analisados não estão disponíveis online ou são edições esgotadas, mimeografadas ou digitalizadas.

A nossa intencionalidade política reflete a "lupa" adotada no processo de buscas no referido sistema eletrônico, os dados levantados e organizados se encerram em nomes masculinos ou em acadêmicos brancos. Assim, compreendemos que a produção dessas autoras negras passa duplamente despercebida pelos recortes adotados; primeiro, por não ser facilmente localizada no sistema supracitado; e segundo, por não ser mencionada pela literatura sistematizada a partir dos resultados obtidos. Para suplementar essas ausências ou lacunas, a revisão teórica apoia-se em discussões advindas das estudiosas e ativistas negras, como, por exemplo, Luiza Bairros (2000) Raquel Andrade Barreto (2005), Elisabeth Viana (2006), Alex Ratts e Flávia Rios (2010), tributárias (os) e/ou contemporâneas (os) de Lélia González e Neusa Santos Souza.

Os fanonismos no Brasil têm se destacado como um campo profícuo nas ciências sociais conforme o mapeamento ${ }^{2}$ contemporâneo realizado pelo sociólogo Deivison Faustino (2015), mas ainda sim, essa recepção tem sido marcada pela literatura de língua inglesa e, no Brasil, por expoentes masculinos das ciências sociais como Guimarães (2008) e Ortiz (2014). Frantz Fanon tem retornado à cena acadêmica, no entanto, quais são as outras figuras que estão por detrás da figura deste intelectual que projetamos somente um portrait vestido de terno escuro, em geral, em uma única imagem em preto e branco? As intelectuais negras brasileiras

2 Esse importante mapeamento também foi realizado "em buscas nos bancos virtuais de trabalhos acadêmicos, a saber: a biblioteca de periódicos da Capes e do Scielo" (FAUSTINO, 2015: 24) durante o seu doutorado no Programa de Pós-Graduação em Sociologia na UFSCar, orientado pelo professor Valter Silvério, intelectual negro e militante histórico. 
dialogam com este martinicano? As intelectuais negras brasileiras estão em diálogo com outras pesquisadoras fanonianas?

Ao final, confirmamos que a disseminação dos discursos das intelectuais negras sofre um embargo duplo; o primeiro, a produção de teorias sociais no seu país de origem (nos países africanos, na Diáspora ou na Europa), haja vista depreende-se que os movimentos políticos, artísticos e intelectuais são associados diretamente aos chamados "pais fundadores" que, por sua vez, negam ou silenciam tais intelectuais conforme nos alerta Tanella Boni (2014: 63), e quando essas obras chegam ao Brasil são marcadas "por uma política (colonial) de tradução que insiste em não incentivar amplas traduções de trabalhos de pessoas negras” (ROCHA, 2018: 50).

\section{Os anos de 1960 a 1970: Fanon sob vistas grossas da ditadura civil- militar?}

Antonio Sérgio Alfredo Guimarães (2008) e Deivison Faustino (2015) têm tecido reflexões salutares sobre a recepção de Fanon no Brasil. Conforme os autores, o primeiro momento da recepção de Frantz Fanon se deu pela via terceiromundista com enfoque político no clássico Os Condenados da Terra traduzido, em 1968. Atualmente, Frantz Fanon é associado às tradições dos Estudos Culturais, Póscoloniais, Decoloniais e African Studies desenvolvidos nos Estados Unidos, Europa e África que, segundo Faustino (2015), corresponde em âmbito internacional a quarta tendência dos estudos fanonianos vigentes desde os anos 1980. Assim, os chamados estudos fanonianos ou fanonismos têm repercutido nas discussões acadêmicas, em movimentos sociais negros e nos programas das esquerdas brasileiras, além disso, muitos eventos e publicações internacionais e nacionais na perspectiva decolonial são tributários do pensamento de Frantz Fanon (Cf. MACÊDO, 2016; BERNARDINOCOSTA; GROSFOGUEL, 2016; BERNARDINO-COSTA et al., 2018).

Em razão duas observações são levantadas por Faustino (2014), o curto lapso de vida do psicanalista martinicano não corresponde ou limita a complexidade do seu pensamento, é possível constatar diferenças notáveis entre o pensamento fanoniano, sua práxis revolucionária e os chamados fanonismos. Dessa forma, esse campo deve ser cartografado no plural a fim de aproximar as contribuições de Frantz Fanon às emergências desses novos estudos. Para compreender a recepção do martinicano e a capilaridade da sua influência nos estudos brasileiros, passaremos a análise do Quadro 1 a seguir que reúne os primeiros resultados encontrados no sistema Google Acadêmico entre 1960 a 1970. Esse primeiro lapso compreende-se como a "primeira fase da embocadura terceiro-mundista que vigorou do final dos anos 1950 até os anos 1970, abrigando autores liberais como Hannah Arendt" (FAUSTINO, 2015: 91). 
Quadro 1. Frantz Fanon entre 1960 a 1970 no Brasil

\begin{tabular}{|c|c|c|}
\hline Abordagens & Publicações & Áreas de Interesses \\
\hline $\begin{array}{c}\text { Tradução e } \\
\text { comentários das } \\
\text { primeiras obras de } \\
\text { Frantz Fanon no } \\
\text { Brasil }\end{array}$ & $\begin{array}{l}\text { FANON, Frantz. L’An V de la Révolution Algérienne. } \\
\text { Ed. François Maspero. Paris, 1959. Resenha Crítica } \\
\text { por Fernando Albuquerque Mourão (1962). Revista } \\
\text { de História (USP). } \\
\text { - FANON, Frantz. (1968). Os Condenados da Terra. } \\
\text { Trad. José Laurêncio de Melo. Rio de Janeiro-RJ: } \\
\text { Civilização Brasileira. }\end{array}$ & Ciências Sociais \\
\hline $\begin{array}{l}\text { Discussões sobre } \\
\text { as independências } \\
\text { africanas; crítica } \\
\text { ao colonialismo, } \\
\text { tendências } \\
\text { pós-coloniais e } \\
\text { anticolonial. }\end{array}$ & $\begin{array}{l}\text { - ZOLBERG, Aristides R (1968). "A estrutura do } \\
\text { conflito político nos novos estados da África } \\
\text { Tropical”. Revista de Ciência Política, FGV, abril/ } \\
\text { junho, pp. 56-98. } \\
\text { BELTRAN, Luis. (1969) “A Problemática dos Estudos } \\
\text { Africanistas", } 27 \text { Revista Brasileira de Estudos } \\
\text { Políticos 71. } \\
\text { RICHERS, Raimar. (1970). "Desenvolvimento: } \\
\text { um desafio social”. Revista de Administração } \\
\text { de Empresas, Rio de Janeiro, 10 (2): 41-69 abr./jun. }\end{array}$ & $\begin{array}{l}\text { Ciência Política (Estudos } \\
\text { Políticos), Ciências } \\
\text { Sociais e Administração. }\end{array}$ \\
\hline $\begin{array}{c}\text { Discussão filosófica } \\
\text { sobre a violência e } \\
\text { crítica a Sartre, Sorel e } \\
\text { Fanon. }\end{array}$ & $\begin{array}{l}\text { - ARENDT, Hannah. (1970). Da Violência. Tradução } \\
\text { de Maria Cláudia Drummond Trindade. Brasília- } \\
\text { DF: Editora UnB. }\end{array}$ & Filosofia \\
\hline
\end{tabular}

Fonte: Do Nascimento, 2018.

O destaque do quadro acima é para as traduções do livro Os Condenados da Terra do martinicano Frantz Fanon, e para a tradução do livro Da Violência da filósofa Hannah Arendt (1970). Os primeiros direitos autorais para o português brasileiro do clássico fanoniano Os Condenados da Terra foram adquiridos pela editora Civilização Brasileira (FANON, 1968). A capa, assinada por Marius Laurltzen Bern, reflete o forte apelo ideológico desde a gradação das cores (vermelha e preta) até a projeção das personagens que ilustram metaforicamente a condição política dos condenados à terra. Como afirma Carina Naufel (2012), a editora foi fundada em 1925 por Monteiro Lobato e Octalees Marcondes Ferreira, mas passou a ser presidida em 1948 pelo editor Ênio Silveira. Depois da entrada deste editor, o catálogo editorial foi modificado e, pela primeira vez, editava-se autores marxistas. Como corroborado por Sandra Reimão (2014), Ênio Silveira foi alvo predileto de apreensões, coações e censuras do Ministério da Justiça (MJ) por meio do Serviço de Censura de Diversões Públicas (SCDP) e do setor do Departamento de Censura de Diversões Públicas (DCDP).

No entanto, parece-nos que ainda não foi explorado quais foram os interesses que motivaram a recepção de um escritor negro como Frantz Fanon para além da 
sua possível associação ao marxismo. Em contrapartida, as parcas citações de Frantz Fanon no Brasil durante o lapso de 1960 a 1970, em certa medida, põe em relevo a negligência das suas contribuições para a agenda política das esquerdas latinoamericanas. Segundo Guimarães (2008) e Ortiz (2014), Fanon seguiu como autor desconhecido pelos ativistas e intelectuais negros e no mundo acadêmico branco até a década de 1970. Nos dados organizados neste escrito, notamos que Fanon aparece citado entre 1960 a 1970 a partir da chave-conceitual do anti-colonialismo que fundamentou a emergência das novas identidades nacionais africanas, é importante ressaltar a participação do martinicano no Movimento Pela Libertação da Argélia (MPLA), a produção dessa época foi organizada no livro intitulado Pour la Révolution Africaine (FANON, 2006).

Mas há aqui uma questão sobre as entrelinhas editoriais brasileiras, de fato, Fanon passou despercebido diante da conjuntura política da ditadura civil-militar, ou apenas foi ignorado por ser um intelectual negro, um revolucionário desde a Argélia? O prefácio escrito pelo filósofo Jean-Paul Sartre jamais foi esquecido entre a comunidade acadêmica brasileira, por outro lado, Faustino (2015) nota que Fanon teve um crescente reconhecimento na medida em que foi apropriado pelos movimentos sociais e intelectuais negros. Guimarães (2008) argumenta que o desconhecimento deste grande teórico no interior das esquerdas brasileiras relaciona-se às condições políticas da tradução realizada no auge ditadura civil-militar, ou seja, época de profunda repressão à contraviolência de líderes, guerrilheiros, pensadores, ativistas perseguidos ou condenados à clandestinidade 3 .

Os sociólogos Guimarães (2008) e Ortiz (2014) concordam que as idéias de Fanon entram no Brasil depois da visita dos filósofos franceses Jean-Paul Sartre e Simone de Beauvoir em razão da ampla circulação da filosofia existencialista nos círculos acadêmicos e militantes do pós-guerra, momento em que se estreitou os laços intelectuais entre este filósofo francês e os pensadores afrodiaspóricos e africanos. Na visita ao Brasil, Sartre não se encontrou com nenhum pensador negro ou pensadora negra, por outro lado, Guimarães (2008) afirma que o texto sartreano Orfeu Negro já havia sido publicado no jornal Quilombo ligado ao Teatro Experimental do Negro $(\mathrm{TEN})^{4}$.

3 Como discutido com profundidade por Karin Sant’Anna Kössling (2005), o complexo repressivo acionado pela polícia política da ditadura civil-militar dos estados de São Paulo e Rio de Janeiro também perseguiu os movimentos sociais negros, inclusive, Frantz Fanon, W.E.B Du Bois e Marcus Garvey eram autores do corpo político-teórico negro, o que chamou a atenção dos órgãos repressivos da época.

4 Há referências importantes sobre a formação dos movimentos sociais negros Cf. CUTI, (Luiz Silva). (1992). E assim disse o velho militante José Correia Leite. São Paulo: Noovba e PEREIRA, Amauri Mendes; SILVA, Joselina da. (2009). O Movimento Negro brasileiro: escritos sobre os sentidos de democracia e justiça social no Brasil. Belo Horizonte-MG: Editora Nandyala. 
Há uma disputa acadêmica que põe em relevo se Jean-Paul Sartre ${ }^{5}$ exerceu tanta influência no pensamento de Frantz Fanon ou não. No Brasil, Renato Ortiz (2014: 427) afirma que o editor da revista L'Esprit, Jean Marie Domenach, considera o pensador martinicano um discípulo sartreano, em suas palavras, "o existencialismo de Fanon carrega um elemento de radicalização do marxismo”. Ao nosso ver, essa associação deve ser compreendida a partir da análise do próprio pensamento de Frantz Fanon que, segundo o sociólogo Deivison Faustino (2015), pode ser considerado como um conjunto de premissas políticas e filosóficas que inaugura um novo campo denominado fanonismos. Esse peso atribuído ao Sartre evidencia a existência de uma cartografia hegemônica do conhecimento que privilegia o circuito francês e, por seu turno, compromete o diálogo ou correspondência deste referido pensador com outros autores dos circuitos árabes e latino-americanos, há que se lembrar que Fanon era caribenho e construiu o seu arcabouço político-teórico sobre/na Argélia.

O espectro sartreano apontado por Guimarães (2008) está sublinhado no escopo de Da Violência da filósofa Hannah Arendt que se detém ao prefácio de JeanPaul Sartre e não propriamente as teses do martinicano Frantz Fanon. Para o pensador martinicano, Orfeu Negro até pode ser considerado um marco no intelectualismo do existir negro, no entanto, a participação dos intelectuais brancos na agenda política, literária e filosófica anticolonialista perpassa por críticas precisas.

E que não nos acusem de anafilaxia afetiva; o que queremos dizer é que não há razão para que André Breton diga que Césaire: "É um negro que maneja a língua francesa como nenhum branco a maneja nos dias de hoje". E mesmo que Breton exprimisse a verdade, não vejo onde residiria o paradoxo, ou algo a salientar, pois, afinal de contas, Aimé Césaire é martinicano e professor da universidade. Mas, retrucarão os negros, é uma honra para nós que um branco como Breton escreva coisas como essas. Continuemos... (FANON, 2008: 50-51).

Os circuitos acadêmicos e políticos seja francês ou inglês são responsáveis por eclipsar diversas mulheres do escopo da vida e obra de Frantz Fanon, muitas vezes, para minimizar a influência ou a participação na sua atividade militante e intelectual, como, por exemplo, Josie Fanon, jornalista francesa e sua esposa, recuperada tardiamente pelo estadunidense Christian Filostrat (2017), organizador da coletânea intitulada Le Dernier Jour de Frantz Fanon. A difusão de Fanon pela chamada epidemia sartreana produziu outros efeitos, em grande medida, considerando a hegemonia do pensamento ocidental nota-se que diversos autores negros passaram a reconhecer

5 Para Katleen Gyssels (2005), poetas e escritores negros sejam guianenses, martinicanos, haitianos e africanos foram tributários do existencialismo sartreano. O francês foi autor de prefácios como Orphée Noir, de 1948, para a Anthologie de la poésie nègre et malgache, organizada pelo senegalês Léopold Sédar Senghor; o ensaio introdutório, escrito em 1956, para a primeira edição de Les Damnés de la terre, do martinicano Frantz Fanon e, por conseguinte, outro ensaio escrito, em 1957, para a obra Portrait du colonisé... do tunisiano Albert Memmi. 
Jean-Paul Sartre como o prefaciador-mor de todos os principais textos inaugurais da Négritude ou dos panafricanismos. Ademais, o reconhecimento deste movimento por filósofos e artistas brancos implicou na formação de uma genealogia masculina que, por sua vez, tem no seu cerne o silenciamento da produção artística, intelectual e acadêmica de Paulette Nardal, a pensadora da "consciência da raça”, Suzanne RoussiCésaire, a defensora do Surrealismo caribenho, Jane Nardal, a editora do jornal La Dépêche Africaine, martinicanas pouco lembradas pelos autores das literaturas negro-africanas (SHARPLEY-WHITING, 2000; BONI, 2014).

Voltando para a análise do Quadro 1, neste período de 1960 a 1970, foi possível localizar a resenha crítica do livro L'An V de la Révolution Algérienne 6 do martinicano Frantz Fanon escrita por Fernando Albuquerque Mourão para a Revista de História da Universidade de São Paulo (USP) anterior, inclusive, a tradução de Os Condenados da Terra. No preâmbulo, há uma breve apresentação biográfica e política do autor, o curioso é que a resenha crítica de Fernando Albuquerque Mourão (1962) não foi identificada no escopo do artigo de Guimarães (2008).

A morte de Frantz Fanon, recentemente ocorrida numa clínica nos Estados Unidos, vítima de câncer, ocorreu posteriormente à leitura deste trabalho na Sociedade de Estudos Históricos. Frantz Fanon nasceu na Martinica, tendo seguido seus estudos superiores na Faculdade de Medicina de Paris, onde foi assistente de psiquiatria, e nos hospitais civis, trabalhando depois nos hospitais da Argélia, onde, em contato direto com as realidades e chocado com a brutalidade da luta, ingressa no FNL. Reparte o seu tempo entre as missões ao estrangeiro, procurando obter auxílio para os refugiados argelinos em Marrocos e na Tunísia, e na assistência médica aos combatentes, quer no front, quer nas suas bases na Tunísia (MOURÃO, 1962: 270).

Interessante notar também que Fernando Albuquerque Mourão (1962) faz referências substanciais aos desdobramentos sociais e psicanalíticos do povo argelino, atualmente, analisados pelas chaves-conceituais do mapeamento contemporâneo organizado por Deivison Faustino (2015), porém, o referido livro segue sem tradução para o português brasileiro. As restrições e perseguições das editoras de esquerda, assim como aos intelectuais, guerrilheiros e políticos foi um traço dos regimes autoritários ressaltado com veemência por Sandra Reimão (2014), mas se os livros de Che Guevara e José Martí, por exemplo, aparecem nas listas dos livros mais censurados, por outro lado, o desconhecimento do martinicano Frantz Fanon confirma-se dado o racismo operado pelas próprias revoluções latino-americanas e pelo mercado editorial nacional. Da mesma forma, podemos aplicar tal raciocínio

6 Atualmente, Heitor Loureiro e Raphaël Maureau (2014) publicaram a tradução do terceiro capítulo deste livro intitulado La Famille Algérienne. Curiosamente, as três versões apresentam diferenças no título. Originalmente, em francês, intitula-se L'an $V$ de la révolution algérienne, em inglês, $A$ Dying Colonialism, em espanhol, Sociologie de una Revolución. 
a rarefeita divulgação do pensamento das várias mulheres racializadas na América Latina e Caribe, líderes, ativistas, guerrilheiras, políticas ou intelectuais deste período, por outro lado, tal gesto corrobora a misoginia dos circuitos revolucionários e da tradição dos estudos negros.

\section{Os anos 1980 e 1990: Lélia González e Neusa Santos Souza leitoras de Frantz Fanon?}

No primeiro lapso entre 1960 a 1970 constatamos a vigência da tradição masculina na recepção da produção fanoniana como ilustrado no corpo da seção anterior. A discussão ou menção ao martinicano Frantz Fanon realizada por uma mulher deu-se no escopo da obra da filósofa Hannah Arendt (1970). As observações realizadas a partir dos resultados do Google Acadêmico e sistematizados no Quadro 2 a seguir confirmam a introdução de novas abordagens fanonianas entre 1980 a 1990, período este correspondente à atividade intelectual e ativista de Lélia González e Neusa Santos Souza. Em âmbito internacional anglófono, os anos 1980 corresponde a quarta fase dos estudos fanonianos conforme o mapeamento organizado pelo sociólogo Deivison Faustino (2015). A crítica que se faz aos chamados estudos fanonianos ou fanonismos é a ausência ou presença rarefeita de mulheres na biografia de Frantz Fanon, sua mãe Eléonore Félicia Médélice e a esposa dele, a jornalista francesa Marie-Joséphe Dublé Fanon, das críticas negras, feministas, escritoras contemporâneas a Fanon, como, por exemplo, a escritora martinicana Mayotte Capécia presa às notas de rodapé ou sublinhada com depreciação por este martinicano (Cf. DO NASCIMENTO, 2017).

No Brasil, vários comentadores se interessam pela personagem Jean Veneuse ${ }^{7}$ do romancista guianense René Maran, ao mesmo tempo, as discussões do mundo acadêmico brasileiro baseiam-se em premissas psicanalíticas e filosóficas que buscam solucionar a questão retórica proposta por Fanon: "que quer o homem negro?" (FANON, 2008: 26). A interlocução com as demais autoras para além das ondas ou fases sobre o pensamento de Frantz Fanon não nos parece ser somente uma questão de tradução, aliás, como defendido pela filósofa brasileira Aline Matos Rocha (2008: 50), perpassa os critérios de quem merece tradução nos debates acadêmicos

7 Personagem do livro Batouala do antilhano René Maran, considerada a primeira obra escrita por um autor negro ganhadora do Prix Goncourt, em 1921. Frantz Fanon (2008) afirma que trata-se de um gênero autobiográfico que denuncia pela perspectiva de um antilhano negro como o racismo afeta as subjetividades do homem negro. Por outro lado, os leitores (grafados no masculino para afirmar as suas benesses patriarcais) têm verdadeiro desinteresse pela personagem Nini, da também antilhana Mayotte Capécia, o livro que enquadra-se no gênero autobiográfico é intitulado Je suis Martiniquaise, e trata do enlace de uma mulher negra com um homem branco (francês), porém, pareceu pouco interessante aos olhos masculinistas. No Brasil, essa discussão é bastante conhecida tanto no rol das ciências sociais e pelos movimentos sociais das mulheres negras que, por sua vez, afirmam como o mito da democracia racial e a ideologia do embranquecimento provocaram desvantagens afetivas e econômicas para este grupo. 
brasileiros, o que "contribui para que a maioria dessas produções [das demais autoras diaspóricas e africanas] permaneçam disponíveis apenas em francês ou inglês”.

Antes de adentrar a análise do quadro propriamente dito é importante uma ponderação metodológica e analítica, relacionar Lélia González, Neusa Santos Souza e Frantz Fanon não implica, necessariamente, assumir a posição corrente nos circuitos negros anglófonos e francófonos, pois o que se percebe, muita vezes, é uma hierarquia que privilegia Frantz Fanon como uma das principais referências dos Estudos Póscoloniais e os intelectuais negros (as) brasileiros (as) como seus intérpretes terceiromundistas. Da mesma forma, este artigo poderia ser uma interlocução direta entre essas duas intelectuais e Virgínia Bicudo, haja vista as três são intelectuais negras e brasileiras. Além disso, ambas têm suas trajetórias acadêmicas marcadas pela dedicação, em menor ou maior grau, à psicanálise. Virgínia Bicudo foi uma socióloga e psicanalista com profunda atividade intelectual nas ciências sociais na mesma fase marcada pelos nomes de Florestan Fernandes, Octávio Ianni e Roger Bastide. No mapeamento dos fanonismos, o sociólogo Deivison Faustino (2015) cita a psicanalista Virgínia Bicudo dada a sua proximidade teórico-conceitual ${ }^{8}$ com o sociólogo Guerreiro Ramos e com o psiquiatra Frantz Fanon, mas a intelectual é lembrada como um “destaque destoante do grupo" crítico da branquidade (FAUSTINO, 2015: 208).

As trajetórias de Lélia González e Neusa Santos Souza são percorridas por fios esparsos, rarefeitos ou organizados a partir das memórias dos militantes e ativistas mais velhos. A literatura mais recente tem demonstrado a dedicação teórico-conceitual dos mais novos em disputar a incorporação dessas autoras no cânone acadêmico, ou seja, são educadores (as) e intelectuais tributários (as) das gerações militantes anteriores que têm chegado desde os últimos dois decênios aos programas de pósgraduação e às cadeiras da docência universitária. Em especial, a biografia de Lélia corresponde a própria memória política e afetiva dos militantes, artistas e ativistas, a sua vida e obra confunde-se com o histórico da luta política dos Movimentos Sociais Negros e do Movimento de Mulheres Negras em âmbito nacional e latino-americano e caribenho como acordado por Luiza Bairros (2000), Alex Ratts e Flávia Rios (2010) e Catalina González Zambrano (2017).

Sobre Neusa Santos Souza há muito pouco escrito sobre a sua história de vida ou sobre o alcance da sua atuação como psicanalista, não que ela não seja mencionada por outras autoras, apenas não tem sido o foco central como Frantz Fanon para Deivison Faustino (2015) e Virgínia Bicudo para Damaceno Gomes (2013). Era uma mulher negra, baiana radicada no Rio de Janeiro, que estudou medicina com ênfase em psiquiatria e dedicou-se à psicanálise lacaniana, além desses fios biográficos coletados em veículos negros ${ }^{9}$, diante disso, não conseguimos reunir outras

8 O período de atividade intelectual da psicanalista Virgínia Leone Bicudo analisado por Janaina Damaceno Gomes (2013) compreende os anos de 1945 a 1955, ou seja, antecede o primeiro período da recepção de Frantz Fanon no Brasil. O foco deste trabalho são Lélia González e Neusa Santos Souza, por uma razão muito clara, ambas foram influenciadas diretamente pela versão espanhola e português brasileiro das obras Pele Negra, Máscaras Brancas e Os Condenados da Terra.

9 "Morre Neusa Santos Souza", no Portal da Fundação Cultural Palmares. Disponível em: <http://www. palmares.gov.br/?p=3166> Acessado em 28 de dezembro de 2018. 
informações. Notamos apenas alguns ruídos da sua solidão afetiva e intelectual, em alguns excertos ela é descrita como uma mulher que não deixava filhos, que não era casada, ${ }^{10}$ e que aos 60 anos despedia-se como mais uma vítima do racismo. Para não cair na dicotomia entre Lélia González, a militante, e Neusa Santos Souza, a psicanalista de consultório, é importante sinalizar que esta última também é descrita pela geração das ativistas da década de 1990 como uma das "guardiãs" do Movimento Negro e do Movimento de Mulheres Negras e, por sua vez, Lélia González também era multidiplomada (em História e Filosofia) como ressaltado por Raquel de Andrade Barreto (2005).

Houve um lapso temporal de quase uma década após a morte de Lélia González, ocorrida em 1994, até que as primeiras produções surgissem em âmbito acadêmico, em geral, foram desenvolvidas por pesquisadoras do ativismo antirracista da década de 1990 como Raquel de Andrade Barreto (2005) e Elisabeth Viana (2006). Atualmente, a organização da coletânea Primavera para as Rosas Negras (GONZALEZ, 2018), iniciativa das organizações pan-africanistas de São Paulo, abre precedentes para novos olhares sobre a produção leliana, muitas vezes, seus textos sequer são conhecidos por um público mais amplo ou mais jovem, talvez, seja esse o tributo que falta para Neusa Santos Souza.

Sobre a produção de Neusa Santos Souza foram localizados textos raros referentes a sua atividade profissional; capítulos de livros sobre psicanálise e coorganização no Seminário X de Lacan, tais produções encontram-se esgotadas no mercado editorial. As demais obras de caráter clínico-profissional já são analisadas há algum tempo pela psicóloga Maria Aparecido Bento (2002), ou seja, o pensamento de Neusa Santos Souza (1983) pode ser apreendido pela sua autonomia de possuir um discurso sobre si mesma, ou por uma prática política e profissional coerente com a sua condição racial e de gênero como corroborado na abertura do seu livro Tornar-se Negro: vicissitudes da identidade do negro brasileiro em ascensão social.

Este livro representa o meu anseio e tentativa de elaborar um gênero de conhecimento que viabilize a construção de um discurso sobre o negro, no que tange à sua emocionalidade. Ele é um olhar que se volta em direção à experiência de ser-se negro numa sociedade branca. De classe e ideologia dominantes brancas. De estética e comportamentos brancos. De exigências e expectativas brancas (SOUZA, 1983: 17).

Depois dessas breves digressões biográficas, faz-se necessário a análise teórica da produção de Lélia González e Neusa Santos Souza à luz das abordagens conceituais identificadas e organizadas no Quadro 2 abaixo em três grupos (i) literatura negra diaspórica e africana e panafricanismos; (ii) estudos sobre racismo à brasileira;

10 "Neusa Santos Souza", as poucas notícias sobre sua morte, escritas por amigos, colegas e por um coletivo negro da UERJ, foram organizadas pelo Memorial Lélia González. Disponível em: <http:// leliagonzalez-informa.blogspot.com/p/neusa-santos-souza.html> Acessado em 29 de dezembro de 2018. 
identidade negra; formação dos movimentos sociais negros e críticas ao mito da democracia racial e (iii) críticas ao capitalismo, ao imperialismo e ao colonialismo no contexto das independências asiáticas e africanas. Dessa forma, se a leitora observar atentamente o Quadro 2 a seguir notar-se-á que os textos das brasileiras Lélia González e Neusa Santos Souza estão identificadas com ícones diferentes em relação aos demais autores, em linhas gerais, mantemos tais autoras incorporadas às abordagens conceituais para não cometer novamente um duplo apagamento ou deixá-las à parte dos demais autores (as) ou em seções menos prestigiosas.

Quadro 2. Frantz Fanon entre os anos de 1980 a 1990 no Brasil

\begin{tabular}{|c|c|c|}
\hline Abordagens: & Publicações & $\begin{array}{l}\text { Áreas de } \\
\text { interesse }\end{array}$ \\
\hline $\begin{array}{l}\text { Literatura negra } \\
\text { diaspórica } \\
\text { e africana; } \\
\text { panafricanismos }\end{array}$ & 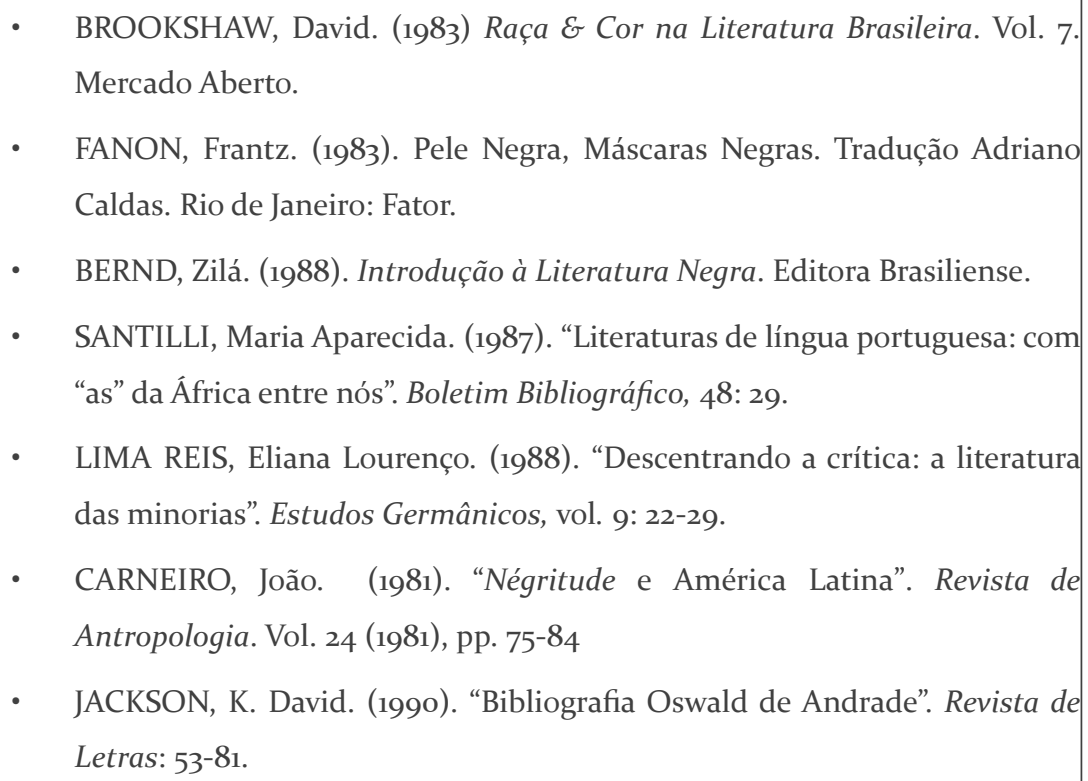 & $\begin{array}{l}\text { Ciências } \\
\text { Sociais }\end{array}$ \\
\hline
\end{tabular}




\begin{tabular}{|c|c|c|}
\hline Abordagens: & Publicações & $\begin{array}{l}\text { Áreas de } \\
\text { interesse }\end{array}$ \\
\hline $\begin{array}{c}\text { Estudos sobre } \\
\text { racismo à } \\
\text { brasileira; } \\
\text { identidade } \\
\text { negra; formação } \\
\text { dos movimentos } \\
\text { sociais negros e } \\
\text { críticas ao mito } \\
\text { da democracia } \\
\text { racial }\end{array}$ & 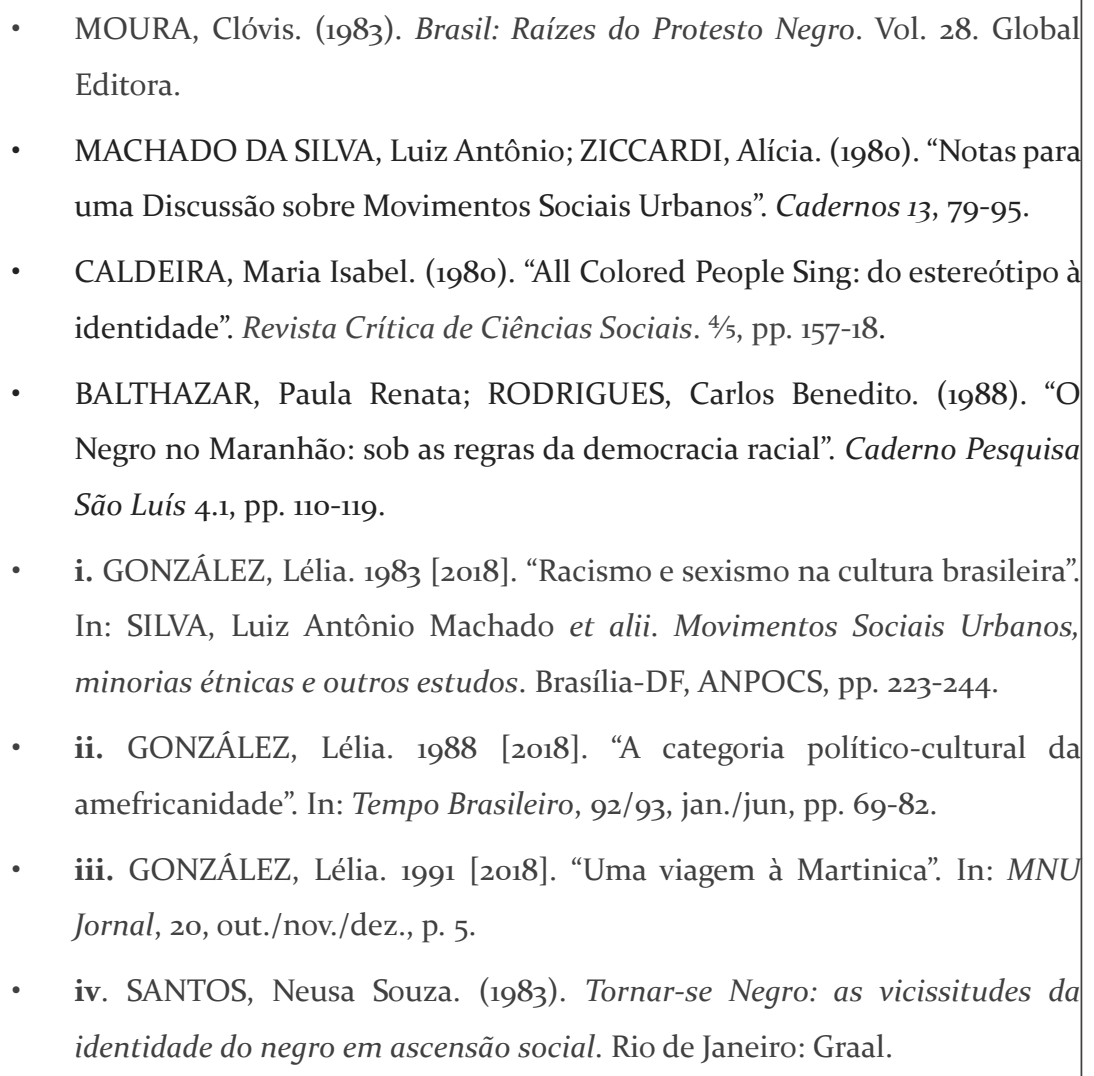 & $\begin{array}{l}\text { Ciências } \\
\text { Sociais }\end{array}$ \\
\hline $\begin{array}{c}\text { Críticas ao } \\
\text { capitalismo, } \\
\text { imperialismo } \\
\text { e colonialismo } \\
\text { no contexto das }\end{array}$ & $\begin{array}{l}\text { - NEVES, Marcelo. (1989). "Da Necessidade de uma Nova Ordem } \\
\text { Internacional”. Revista Brasileira Estudos Políticos, v. 69, p. 7. } \\
\text { - } \text { ALMEIDA DINIZ, Arthur José. (1984). "Hoje Vivemos o Medo". Revista da } \\
\text { Faculdade de Direito da UFMG, vol. 29.26-27, pp.: 80-93. } \\
\text { - LIMA, Bertúlio, LÚCIA, Dora. (1988). “Apartheid:racismoe/ou capitalismo?". } \\
\text { Sequência: Estudos Jurídicos e Políticos, 9.16: 116-123. } \\
\text { - LIMA BASTOS, HERZILA Maria. (1987). "Aspectos culturais de povos } \\
\text { desenvolvidos e subdesenvolvidos como caracterizadores dos seus contatos } \\
\text { com línguas estrangeiras: uma correlação possível". Estudos Germânicos, v. } \\
\text { 8, n. 2, p. 40-44. } \\
\text { STUDER, Caren Elisabeth. (1989). Escola, estrangeiro e violência cultural: } \\
\text { uma contribuição para o entendimento de neocolonialismo cultural. } \\
\text { Dissertação (Mestrado em Metodologia de Ensino). Programa de Pós- } \\
\text { Graduação em Educação, Faculdade de Educação da Unicamp, Campinas, } \\
\text { mimeo. }\end{array}$ & $\begin{array}{l}\text { Ciências } \\
\text { Sociais }\end{array}$ \\
\hline
\end{tabular}

Fonte: Do Nascimento, 2018.

Para Luiza Bairros (2000), Racismo e sexismo na cultura brasileira é o texto mais emblemático do pensamento leliano. Ainda conforme a socióloga, o que atribui peso nas reflexões de Lélia González é "o uso de categorias propostas por Freud e 
Lacan que também aparecem em seus trabalhos posteriores, e resulta da tentativa de desvendar o que fica sem explicação no racismo à brasileira" (BAIRROS, 200o: 353). Em contrapartida, A categoria político-cultural da amefricanidade e Uma viagem à Martinica são produções advindas da agenda latino-americana e caribenha entre 1980 a 1990 como assinalado por Alex Ratts e Flávia Rios (2010), pois interrelacionam as lutas dos negros das Américas às ideologias vivificadas durante as libertações africanas e afro-diaspóricas.

Dessa forma, ao disputar a presença nesses espaços, Lélia González demonstra se situar politicamente em dois movimentos quais sejam, a busca pela inserção das intelectuais brasileiras nas agendas transnacionais, historicamente, inauguradas pelos encontros de negros diaspóricos e africanos, e por outro lado a filósofa compreende a importância de alinhar a escala regional (América Latina e Caribe) a nacional (Brasil) para concretizar os interesses dos Movimentos Sociais Negros e do Movimento de Mulheres Negras (ZAMBRANO, 2017). A necessidade de afirmar as contribuições de Lélia González e Neusa Santos Souza ou pensá-las como leitoras de Frantz Fanon (1968 e 2008), é propor uma reflexão sobre a importância da circulação das traduções deste martinicano no país, e afirmar que trata-se de uma agenda política protagonizada por mulheres negras que desenvolveram teoricamente os debates raciais no Brasil no período de 1980 a 1990.

A referência a Frantz Fanon foi constante nos movimentos negros de Brasil e Estados Unidos e revelam a consciência global do racismo. A importância do autor, entre outras coisas, esteve em criticar uma sociedade centrada no branco e na obsessão pela brancura, ao mesmo tempo, destacar os dois pólos de uma relação colonial: o colonizador e o colonizado. Fanon buscou compreender os mecanismos de dominação na formação da consciência do povo colonizado (BARRETO, 2005: 86).

Deivison Faustino (2015) afirma que as versões de Pele Negra, Máscaras Brancas circulava desde 1970 em duas versões português e castelhano, esta última curiosamente intitulada!Escucha, Blanco. Conforme Elisabeth Viana (2006), Lélia González participava desde a década de 1960 do mundo acadêmico como tradutora e, mais tarde, como professora universitária. Desse modo, é importante salientar que a filósofa ambientou-se com as discussões psicanalíticas antes mesmo da tradução dos clássicos fanonianos para o Brasil, ao seu currículo soma-se cerca de quatro traduções de compêndios da área como Freud e a Psicanálise do francês Octave Mannoni, fato que confirma o seu know-how na formação teórico-conceitual dos movimentos sociais negros, além, é claro, dos cargos ocupados durante a sua vida como professora e coordenadora do curso de Ciências Sociais. 
Segundo um importante manual ${ }^{11}$ da área da Psicanálise, Pele Negra, Máscaras Brancas (FANON, 2008):

Era uma resposta à Psicologia da Colonização, obra do psicanalista francês Octave Mannoni, publicada em 1950. Mesmo julgando "sincero" o procedimento de seu adversário, Fanon o acusava de psicologizar a situação colonial e reduzir os conflitos entre o homem branco e o homem negro a um jogo sofisticado, que levava a manter o colonizado na dependência do colonizador. (ROUDINESCO E PLON, 1998: 222).

Desse modo, conforme Monique Pfau (2012: 61) a tradução implica na transcodificação, ou seja, "os [as] tradutores [as] devem ter em mente e claramente compreendido os discursos dos autores dos textos originais", e no caso de Lélia González além da sua fluência em francês trata-se também de uma das mais importantes intelectuais negras. Dessa forma, a sua aproximação com autores negros da francofonia como Cheik Anta Diop e Frantz Fanon, deve-se a sua excelência acadêmica notada nas suas análises grandiloquentes, sua atividade profissional como tradutora e sua aproximação crítica nos chamados estudos das relações raciais. Outro ponto diferencial desta filósofa foi a sua consciência multiescalar (transnacional, regional e nacional) em relação a Diáspora e o continente africano, afinal, a experiência colonial entremeou-os historicamente, no entanto, havia a emergência anticolonial da identidade negra representada por trocas políticas e culturais.

Em contrapartida, a atividade profissional Lélia González não se encerra no campo da psicanálise, a filósofa também se interessou por autores canônicos ocidentais, bem como autores africanos e diaspóricos. Lélia González foi leitora de Marx, Cheik Anta Diop, George C. M. James, Ivan Van Sertima, Walter Rodney e Simone de Beauvoir, esta última partilhada pelas mesmas leituras da psicanalista Neusa Santos Souza. Entretanto, ao amadurecer os seus pressupostos filosóficos e, principalmente, após suas atuações como ativistas em organizações negras ou de mulheres negras, ambas perceberam que a agenda feminista hegemônica (classe média branca) diferencia-se da realidade vivenciada pelas mulheres negras (RATTS E RIOS, 2010).

Os quadros apresentados no decorrer deste artigo são importantes para refletir sobre a (não) inserção do pensamento de Lélia González e Neusa Santos Souza no escopo das abordagens conceituais em voga nos chamados estudos fanonianos. Dessa forma, o pensamento das intelectuais negras brasileiras não têm sido sistematizado em "fases" como notado em relação ao martinicano Frantz Fanon, este detalhe não atende aqui o antagonismo que se faz entre o ativismo antirracista/feminista e a produção acadêmica, mas desvela a lógica sexista que busca homogeneizar os

11 Coma colaboração dos estudos desenvolvidos por Françoise Vergès sobre o movimentoantipsiquiátrico inaugurado por Fanon, Roudinesco e Plon (1998) identifica que o psiquiatra utilizava os conhecimentos da psicanálise para rejeitar o freudismo em nome de uma política anticolonial, ou seja, o seu legado até hoje tem sido desenvolvido naquilo que se denomina de etnopsicanálise ou antropologia psicanalítica. 
processos intelectuais individuais e coletivos das mulheres negras ou reduzi-los em seções menos prestigiosas no rol dos "Estudos Raciais" ou dos "Estudos de Gênero". Frantz Fanon também produziu a sua obra a partir da sua práxis revolucionária (como Lélia González) e da sua experiência profissional como psiquiatra (Neusa Santos Souza também o era), mas, atualmente, não é visto como militante ou simplesmente revolucionário. Frantz Fanon é o Autor ou o próprio marco conceitual de um campo, o que se percebe é a complexificação das suas contribuições na medida em que é recuperado e partilhado por diversos autores/gerações (inclusive brancos/ acadêmicos) no escopo de novos estudos do Norte e Sul Global que, mormente, ainda excluem o Brasil dessa nova (ou velha?) cartografia do conhecimento.

A marfinense Tanella Boni (2014) questiona o consenso que há no circuito internacional negro e no mundo acadêmico, pois ambos associam o marco temporal do Movimento Négritude às obras inaugurais dos homens negros. Ao transpor tal crítica para nossa proposta, é possível demonstrar a vigência da genealogia masculinista também no Brasil que, por seu turno, tem previsto a participação das mulheres negras nas demandas das agendas políticas ou nas produções acadêmicas a partir das categorias de "gênero" ou "feminismos". Negar que a práxis política destas mulheres não têm fundamento teórico-conceitual ou limitá-las em certos debates implica, mais uma vez, em hierarquizá-las na cartografia hegemônica do conhecimento da qual situam-se sempre na "periferia" em relação à produção masculina ou branca (sinônimo de centro/cânone). Ou seja, as mulheres negras têm a sua atuação em movimentos sociais transformada em estratégias pedagógicas para ensinar o (a) branco (a) ou o homem sobre os seus privilégios na sociedade, enquanto os homens operam a produção do pensamento social e político que, por conseguinte, institucionaliza-se como teoria social.

Nesse simulacro, a lógica sexista reproduz a origem das teorias canônicas ou ditas de vanguarda à imagem e semelhança dos autores masculinos, neste caso, associados sempre a figura do "pai" da teoria x ou y. Notamos que são os autores que gozam do mérito de ser reconhecidos com os "pais" deste ou daquele movimento ou teoria, inclusive, eles só aceitam dividir esse poder com outros homens. Como afirmado por Tracy D. Sharpley-Whiting (2000) artistas, escritoras e pensadoras negras são eclipsadas mesmo que elas estejam na vanguarda filosófica, cultural e artística do mesmo movimento. Se se inverter a lógica algo parece fugir a fluidez deste texto, afirmamos que Suzanne Roussi-Césaire, Jeanne Nardal e Paulette Nardal são as "mães" do Movimento Négritude, e que Lélia González e Neusa Santos Souza são as "mães" dos fanonismos no Brasil, algo soa estranho? O contrário em relação aos homens é tomado como verdadeiro, os leitores (assinado em masculino e no plural para evidenciar os seus grupos) sequer desconfiam que nessa relação bilateral os "pais fundadores" jamais atribuem a devida importância às "mães". 


\section{Considerações Finais}

Ao longo deste artigo, buscamos trazer à tona a importância das novas abordagens sobre a produção da filósofa Lélia González e da psicanalista Neusa Santos Souza a partir da interface com os fanonismos no Brasil. Duas questões centrais incitaram o nosso debate; a primeira, as intelectuais negras brasileiras estão em diálogo com o martinicano Frantz Fanon? Essa questão é positiva para as leitoras e interlocutoras que se atenta às discussões filosóficas e psicanalíticas dessas duas intelectuais brasileiras. Podemos afirmar também que o pensamento do martinicano teve ressonância porque tratou-se de uma leitura partilhada por diversas ativistas (individualmente ou coletivamente) que privilegiaram a práxis revolucionária nos programas das organizações negras entre 1970 a 1990. Em razão, a "excepcionalidade" para Frantz Fanon aqui marca o seu crescente interesse nas discussões acadêmicas anglófonas e francófonas, ao final, são introduzidas no Brasil pela via da genealogia masculinista. Repensar o silenciamento das pensadoras negras em âmbito internacional, regional e nacional é se comprometer, de fato, com o processo de descolonização do conhecimento, e não cristalizar esse círculo vicioso que recupera somente nomes masculinos.

Se nos atentarmos para o trânsito dessas teorias políticas em âmbito internacional podemos esboçar um modelo que não obedece uma lógica linear, mas que evidencia as regras da cartografia do conhecimento operada pelos marcadores da língua, nacionalidade ou grupo de pessoas (mulheres negras brasileiras, por exemplo): Frantz Fanon (francês) - Comentadores/Teóricos (inglês e francês) - Teorias tributárias (inglês e espanhol). Agora se invertermos o modelo pela lógica territorial ou identitária temos o seguinte: Frantz Fanon (Martinica-Antilhas/Argélia-África) Comentadores/Teóricos (África, Ásia, Estados Unidos e Europa)- Teorias Tributárias (América Latina, África e Ásia). Logo, em termos de escala regional, Lélia González e Neusa Santos Souza não se encontram tão distantes do martinicano por questões históricas, raciais, culturais e políticas, afinal, são duas latino-americanas e um caribenho, mas se distanciam em razão do gênero (mulheres negras e homem negro), além de outros marcadores.

Essa digressão não busca reivindicar benesses ou culpas ao martinicano Frantz Fanon, não buscamos individualizar sujeitos oprimidos pela mesma estrutura colonial-imperialista. O intuito é instigar o exercício crítico que confirma como o racismo e o sexismo afetam grupos heterogêneos do mesmo espectro de maneiras diversas. A segunda questão inicial deste artigo, as intelectuais negras brasileiras estão em diálogo com outras pensadoras fanonianas (ou suas críticas)? Pelo mapeamento contemporâneo organizado por Faustino (2015) percebemos que muito pouco tem refletido nos debates brasileiros, em geral, os artigos mais citados no Google Acadêmico são assinados por uma autoria masculina ou agrupadas a partir de temas específicos como os Estudos Pós-Coloniais e Decoloniais. A predominância dessas referências contribui para que os fanonismos seja uma prerrogativa exclusiva para pesquisadores 
que alcançam os doutorados sanduíches no exterior ou em intercâmbios intelectuais em estágios pós-doutorais em universidades estrangeiras, por exemplo. Ao retornar ao Brasil, esses pesquisadores têm ampla abertura em periódicos nacionais, mas raramente citam as autoras negras do circuito internacional, ademais, os estudos comparativos também excluem as referência negras brasileiras.

À guisa das considerações finais, pontuamos a questão da tradução/recepção da produção diaspórica e africana. A nova tradução espanhola de Pele Negra, Máscaras Brancas (FANON, 2009), por exemplo, é realizada na íntegra e coletivamente por mulheres $^{12}$. No Brasil, a segunda versão desta mesma tradução têm os seus direitos reservados para a editora da Universidade Federal da Bahia (UFBA) que, de certa forma, minimiza a hegemonia acadêmica e editorial centrada no eixo Centro-Sul Ao desvelar a genealogia masculinista em disputa pelos fanonismos no Brasil, esperase que haja reflexões pertinentes sobre uma possível inserção dos debates propostos por Tracy Denean Sharpley-Whiting, afinal, essa intelectual também tem produções críticas sobre Frantz Fanon desde os anos 1990 em parceria com outras acadêmicas. Não é para duvidar que ainda não haja o reconhecimento desta pensadora e das intelectuais brasileiras ou das tradutoras negras?

Agradecimentos: Sou grata as cientistas sociais Hellen Rodrigues e Maysa Camelo e a filósofa Ana Carolina Magalhães Gonzaga pelas primeiras sugestões e críticas, em especial, agradeço pelo incentivo em tornar este texto público.

\section{Referências bibliográficas}

ALMEIDA DINIZ, Arthur José. (1984). "Hoje Vivemos o Medo”. Revista da Faculdade de Direito da UFMG, vol. 29.26-27, pp.: 80-93.

AMAURI MENDES; SILVA, Joselina da. (2009). O Movimento Negro brasileiro: escritos sobre os sentidos de democracia e justiça social no Brasil. Belo Horizonte-MG: Editora Nandyala.

ARENDT, Hannah. (1970). Da Violência. Tradução Maria Cláudia Drummond Trindade, Brasília-DF: Editora UnB.

BALTHAZAR, Paula Renata; RODRIGUES, Carlos Benedito. (1988). "O Negro no Maranhão: sob as regras da democracia racial”. Caderno Pesquisa São Luís 4.1, pp. 110119.

12 Respectivamente a listagem das tradutoras da última edição espanhola, Iría Álvarez Moreno pelos textos da filósofa Judith Butler e Sylvia Wynter; Paloma Monleón Alonso pelos textos de Lewis R. Gordon e Nelson Maldonado-Torres e, por fim, Ana Useros Martín pelos textos de Frantz Fanon, Samir Amin e Immanuel Wallerstein. 
BARRETO, Raquel Andrade. (2005). Enegrecendo o Feminismo ou Feminizando a Raça: Narrativas de Libertação em Angela Davis e Lélia Gonzalez. Dissertação de Mestrado (História Social da Cultura), Departamento de História da PUC - Rio, Rio de Janeiro.

BAIRROS, Luiza. (2000). “Lembrando Lélia Gonzalez”. no 23, Afro-Ásia, pp. 2-22.

BELTRAN, Luis. (1969) "A Problemática dos Estudos Africanistas", Revista Brasileira de Estudos Políticos 71.

BERND, Zilá. (1988). Introdução à Literatura Negra. Editora Brasiliense.

BENTO, Maria Aparecida. (2002)."Branqueamento e branquitude no Brasil”. In: CARONE, Iray; BENTO, Maria Aparecida. Psicologia social do racismo. Petrópolis: Vozes.

BERNARDINO-COSTA, Joaze. GROSFOGUEL, Ramón. (2016). Decolonialidade e Perspectiva Negra. Revista Sociedade e Estado, Volume 31, Número 1, Janeiro/Abril.

BERNARDINO-COSTA, Joaze et al., (2018). Decolonialidade e Pensamento Afrodiaspórico. São Paulo: Editora Autêntica.

BRASIL (2008). Morre Neusa Santos Souza”, no Portal da Fundação Cultural Palmares. Disponível em: <http://www.palmares.gov.br/?p=3166> Acessado em 28 de dezembro de 2018.

BROOKSHAW, David. (1983) Raça E Cor na Literatura Brasileira . Vol. 7. Mercado Aberto.

BONI, Tanella. (2014). "Femmes en Négritude: Paulette Nardal et Suzanne Césaire". Rue Descartes, v. 4, n. 83, p. 62-76.

CALDEIRA, Maria Isabel. (1980). "All Colored People Sing: do estereótipo à identidade”. Revista Crítica de Ciências Sociais, pp. 157-18.

CARNEIRO, João. (1981). “ Négritude e América Latina”. Revista de Antropologia. Vol. 24 (1981), pp. 75-84

CUTI, Luiz Silva. (1992). E assim disse o velho militante José Correia Leite. São Paulo: Noovba.

FANON, Pele Negra, Máscaras Brancas. (2008). Tradução de Renato da Silveira. Salvador: EdUFBA. 
. (1959). L’An V de la Révolution Algérienne. Ed. François Maspero. Paris.

. (1962). L'An V de la Révolution Algérienne. Ed. François Maspero. Paris, 1959. resenha Crítica. Resenha Crítica por Fernando Albuquerque Mourão. Revista de História (USP).

. (1968). Os Condenados da Terra. Tradução de José Laurêncio de Melo. Rio de Janeiro: Civilização Brasileira.

(1983). Pele Negra, Máscaras Negras. Tradução de Adriano Caldas. Rio de Janeiro: Fator.

(2006). Pour la révolution africaine: écrits politiques. Paris: La Découverte.

(2009). Piel Negra, Máscaras Blancas. Madri-Espanha: Edições Akal.

FAUSTINO, Deivison. (2015). "Por que Fanon? Por que agora?": Frantz Fanon e os fanonismos no Brasil. Tese (Doutorado). Universidade Federal de São Carlos-SP. São Carlos: UFSCar.

FILOSTRAT, Christian. (2017). Le dernier jour de Frantz Fanon: un récit d'un acte suivie d'un entretien avec Josie Fanon, sa femme. Lake Oswego, Oregon/USA: Pierre Kroft Legacy Publishers.

GOMES, Janaína Gomes. (2013). Os Segredos de Virgínia Leone Bicudo: Estudo de Atitudes Raciais em São Paulo (1945-1955). Tese (Doutorado) Universidade de São Paulo (USP). Faculdade de filosofia, Letras e Ciências Humanas. Departamento de Antropologia. Programa de Pós-Graduação em Antropologia Social. São Paulo-SP.

GONZÁlEZ, Lélia Almeida. (2018). Primavera para as Rosas Negras. São Paulo: Diáspora Africana. (Coletânea da União dos Coletivos Pan-africanistas).

. 1983 [2018]. "Racismo e sexismo na cultura brasileira”. In: SILVA, Luiz Antônio Machado et alii . Movimentos Sociais Urbanos, minorias étnicas e outros estudos. Brasília-DF, ANPOCS, pp. 223-244.

. 1988 [2018]. “A categoria político-cultural da amefricanidade”. In: Tempo Brasileiro , 92/93, jan./jun, pp. 69-82.

1991 [2018]. "Uma viagem à Martinica”. MNU Jornal, 20, out./nov./dez., p. 5.

GUIMARÃES, Antonio Sérgio Alfredo. (2008). A recepção de Fanon no Brasil e a identidade negra. In: Novos estudos - CEBRAP, São Paulo, n. 81. 
GYSSELS, K. (2005). "Sartre postcolonial? Relire Orphée noir plus d'un demi-siècle après". Cahiers d'études africaines, pp. 631-650.

HERKENHOFF, Alfredo (2009). Racismo: Por que se Matou a psicanalista negra que fazia sucesso no Rio? Disponível em: <https://mamapress.wordpress.com/2016/o8/o3/ racismo-por-que-se-matou-a-psicanalista-negra-que-fazia-sucesso-no-rio/ Acessado em 29 de dezembro de 2018.

JACKSON, K. David. (1990). “Bibliografia Oswald de Andrade”. Revista de Letras, pp. $53-81$.

KÖSSLING, Karin Sant'Ana. (2007). As lutas antirracistas de afrodescendentes. sob vigilância do DEOPS (1964-1983). Dissertação (Mestrado) Universidade de São Paulo (USP). Faculdade de Filosofia, Letras e Ciências Humanas. Departamento de História. São Paulo-SP.

LIMA BASTOS, HERZILA Maria. (1987). "Aspectos culturais de povos desenvolvidos e subdesenvolvidos como caracterizadores dos seus contatos com línguas estrangeiras: uma correlação possível”. Estudos Germânicos, v. 8, n. 2, p. 40-44.

LIMA REIS, Eliana Lourenço. (1988). “Descentrando a crítica: a literatura das minorias”. Estudos Germânicos, vol . 9: 22-29.

LIMA, Bertúlio, LÚCIA, Dora. (1988). “Apartheid: racismo e/ou capitalismo?”. Sequência: Estudos Jurídicos e Políticos, 9.16, pp.116-123.

LOUREIRO, Heitor, MAUREAU, Raphaël. (2014). "A família argelina (Frantz Fanon)”. Revista África, São Paulo. v. 33-34, p. 121-139.

MACEDO, José Rivair. (2016). O pensamento africano no século XX. São Paulo: Outras expressões.

MACHADO DA SILVA, Luiz Antônio; ZICCARDI, Alícia. (1980). "Notas para uma Discussão sobre Movimentos Sociais Urbanos”. Cadernos 13, pp. 79-95.

MOURA, Clóvis. (1983). Brasil: Raízes do Protesto Negro. Vol. 28. Global Editora.

NAUFEL,, Carina da Rocha. (2012). A capa convida: o design gráfico de Marius Lauritzen Bern para a editora Civilização Brasileira. 159 p. Dissertação (Mestrado). Universidade Estadual de Campinas, Instituto de Artes: Campinas-SP.

NASCIMENTO, Rosânia do. (2017). "Femmes en négritude: intelectuais negras silenciadas”. Entre-Lugar, Dourados-MS, v. 7, n.13, pp. 10-20. 
NEVES, Marcelo. (1989). “Da Necessidade de uma Nova Ordem Internacional”. In: Revista Brasileira Estudos Políticos , v. 69, p.7.

PFAU, Monique. (2012). "Gênero e Tradução: Questões culturais sobre a transmissão de conhecimento”. Revista Criação e Crítica, v. 8: p. 56-64, UFSC. Disponível em: <http://www.revistas.usp.br/criacaoecritica/article/view/46842> Acessado em 15 de março de 2019.

RATTS, Alex; RIOS, Flávia. (2010). Lélia González (Retratos do Brasil Negro). São Paulo: Selo Negro.

REIMÃO, Sandra. (2014). "Proíbo a publicação e circulação... censura a livros na ditadura militar". Estudos Avançados 28 (80), pp. 75-90.

RICHERS, Raimar. (1970). "Desenvolvimento: um desafio social”. Revista de Administração de Empresas, Rio de Janeiro, 10 (2): 41-69 abr./jun.

ROCHA, Aline Matos. (2018). Corporal (idade) discursiva à sombra da hierarquia e do poder: a relação entre Oyěwùmí e Foucault. Dissertação (Mestrado). Universidade Federal de Goiás- UFG: Faculdade de Filosofia, Programa de Pós-graduação em Filosofia. Goiânia-GO.

ROUDINESCO, Elisabeth, PLON, Michel. (1998). Dicionário de Psicanálise. Tradução de Vera Ribeiro e Lucy Magalhães. Rio de Janeiro: Zahar.

ORTIZ, Renato. (2014). "Frantz Fanon: um itinerário político e intelectual”. Revista Contemporânea, n. 4, n. 2: p. 425-442 Jul.-Dez. Disponível em: <https://www. kilombagem.net.br/wp-content/uploads/2015/o7/Fanon-Ortiz-.pdf Acessado em 14 de março de 2019.

SANTILLI, Maria Aparecida. (1987). "Literaturas de língua portuguesa: com "as" da África entre nós”. Boletim Bibliográfico, 48: 29.

SANTOS,S. Neusa. (1983). Tornar-se Negro: as vicissitudes da identidade do negro em ascensão social. Rio de Janeiro: Graal.

SHARPLEY-WHITING, Tracy. (2000). "Femme Négritude: Jane Nardal, La Dépêche Africaine and the Francophone New negro". Souls, fall, pp. 8-17.

STUDER, Caren Elisabeth. (1989). Escola, estrangeiro é violência cultural: uma contribuição para o entendimento de neocolonialismo cultural. Dissertação (Mestrado em Metodologia de Ensino). Programa de Pós-Graduação em Educação, Faculdade de Educação da Unicamp, Campinas. 
VIANA, Elizabeth do Espírito Santo. (2006). Relações raciais, gênero e movimentos sociais: o pensamento de Lélia Gonzalez 1970-199o. Dissertação (Mestrado em História Comparada), Departamento de História, CFCH/IFCS/UFRJ, Rio de Janeiro.

ZAMBRANO, Catalina González. (2017). Mulheres negras em Movimento: Ativismo Transnacional na América Latina (1980-1995). Tese (Doutorado). Universidade de São Paulo (USP). Faculdade de Filosofia, Letras e Ciências Humanas. Programa de PósGraduação em Sociologia. São Paulo-SP. 